\title{
Large sample size in child and adolescent psychiatric research: the way of salvation?
}

\author{
Veit Roessner
}

Published online: 6 November 2014

(c) Springer-Verlag Berlin Heidelberg 2014

As in other medical fields, the shift toward scientific-based clinical practice in both diagnostics and treatment is ongoing in child and adolescent psychiatry [9]. However, numerous characteristics more or less specific for our field impede the generation of evidence and therefore in the end the implementation of evidence-based guidelines. Three examples serve to illustrate this impediment. (1) The low level of introspection of young subjects reduces diagnostic accuracy. (2) The high rates of comorbidity limit specificity and generalization of findings. (3) The requirement of caregivers' consent for study participation hampers recruitment efforts. Such issues entail the frequently posed question: "How large is the impact and cost-benefit ratio of the different sampling methodologies, i.e., comparing register-based versus clinically selected versus single case studies [8] ?"

Interestingly, in the current issue of European Child and Adolescent Psychiatry there is only one randomized controlled trial (RCT). Van den Hoofdakker et al. [12] explored the influence of paternal variables on the outcome of behavioral parent training (BPT) in $n=83$ children with attention-deficit/hyperactivity disorder (ADHD) by comparing a group receiving BPT plus ongoing routine clinical care (RCC) versus an RCC alone group. This is all the more noteworthy as across the medical sciences RCTs are often considered as the most important source of evidence. But RCTs face important ethical and logistical constraints, particularly in children and adolescents with the consequence of, e.g., smaller sample sizes and shorter

V. Roessner $(\bowtie)$

Department of Child and Adolescent Psychiatry,

TU Dresden, Fetscherstrasse 74, 01307 Dresden, Germany

e-mail: Veit.Roessner@uniklinikum-dresden.de observation periods. In addition, RCTs have been criticized for focusing on highly selected populations and outcomes.

All the other findings in the current issue are based on much larger sample sizes. Four studies used questionnaires in large samples of children and adolescents $[1,2,5,7]$. One population-based study rendered possible via linkage of records of three health data sets compared disordered (ADHD; $n=11,902$ ) and non-disordered children (healthy controls; $n=27,304)$ under 18 years [11]. Two reviews, one on studies which reported white matter/gray matter changes in pediatric and adolescent bipolar disorder/unipolar depression, as detected by diffusion tensor imaging and voxel-based analysis [10], and the other providing an overview of ASD screening studies and ongoing programs across Europe [4], also report findings on large cumulated total samples of clinically diagnosed patients.

But do studies with larger sample sizes result regularly in findings of higher quality or relevance?

First, the advantages of a large sample size include a more precise estimate of the effect size and an easier assessment of the representativeness of the sample and the generalizability of the achieved results. However, a small effect size may not prove to be of clinical relevance. In addition, both selection bias and the negative impact of confounders need to be considered with care. The reduced number of variables and/or quality of data (e.g., due to confirmation bias) can even prevent correction for known confounders. This is a disadvantage of non-RCT studies, because in RCTs all potential confounders (known or unknown) are expected to be evenly distributed between the groups being compared.

Second, the aggregation of findings by conducting (systematic) reviews and meta-analyses produces large numbers. However, several methodological experts point out that the quality of reporting is inconsistent and suggest 
that readers should not accept the respective findings uncritically (e.g., [6]). One reason for this admonition is the fact that inaccurate reporting of data hampers the generalizability and the correct interpretation of the results. Another source of limited quality is the incorrect or imprecise use of terminology. While there are multitudinous, mostly very specialized initiatives for unification of terminology, two initiatives included in the Enhancing the Quality and Transparency of Health Research (EQUATOR) international network, the Consolidated Standards Of Reporting Trials (CONSORT), and Strengthening the Reporting of Observational Studies in Epidemiology (STROBE) have elaborated appropriate guidelines to improve transparence, clearness, and completeness of scientific literature. The CONSORT statement consists of a 25 items checklist and a flowchart diagram which provide guidance to authors on how to report randomized clinical trials. The STROBE is a checklist of 22 items which should be addressed when observational studies (case-control, cohort, and cross-sectional) are designed. Many editorial committees and prestigious scientific journals have embraced these guidelines to improve the quality and methodology of their reported findings [3].

Last but not least, all findings in the present issue are derived from cross-sectional studies only. However, only longitudinal studies can provide data suitable for sophisticated statistical analysis of change over time and potentially enable researchers to predict cause-effect relationships. Additionally, longitudinal studies allow us to analyze and predict long-term or cumulative effects which are normally hard to analyze in a cross-sectional study. In view of the aforementioned numerous characteristics relevant to the field of child and adolescent psychiatry, longitudinal studies are of inestimable value because several parameters, e.g., key risk exposures and their interplay with genes, are likely to vary across development [13].

\section{References}

1. Adriaanse M, Veling W, Doreleijers T, van Domburgh L (2014) The link between ethnicity, social disadvantage and mental health problems in a school-based multiethnic sample of children in the
Netherlands. Eur Child Adolesc Psychiatry 23(11). doi:10.1007/ s00787-014-0564-5

2. Basten M, van der Ende J, Tiemeier H, Althoff RR, Rijlaarsdam J, Jaddoe VWV, Hofman A, Hudziak JJ, Verhulst FC, White T (2014) Nonverbal intelligence in young children with dysregulation: the generation R study. Eur Child Adolesc Psychiatry 23(11). doi:10.1007/s00787-014-0551-x

3. Bolignano D, Mattace-Raso F, Torino C, D'Arrigo G, Abd ElHafeez S, Provenzano F, Zoccali C, Tripepi G (2013) The quality of reporting in clinical research: the CONSORT and STROBE initiatives. Aging Clin Exp Res 25:9-15

4. García-Primo P, Hellendoorn A, Charman T, Roeyers H, Dereu M, Roge B, Baduel S, Muratori F, Narzisi A, Van Daalen E, Moilanen I, de la Paz MP, Canal-Bedia R (2014) Screening for autism spectrum disorders: state of the art in Europe. Eur Child Adolesc Psychiatry 23(11). doi:10.1007/s00787-014-0555-6

5. Kaess M, Durkee T, Brunner R, Carli V, Parzer P, Wasserman C, Sarchiapone M, Hoven C, Apter A, Balazs J, Balint M, Bobes J, Cohen R, Cosman D, Cotter P, Fischer G, Floderus B, Iosue M, Haring C, Kahn J-P, Musa GJ, Nemes B, Postuvan V, Resch F, Saiz PA, Sisask M, Snir A, Varnik A, Žiberna J, Wasserman D (2014) Pathological Internet use among European adolescents: psychopathology and self-destructive behaviours. Eur Child Adolesc Psychiatry 23(11). doi:10.1007/s00787-014-0562-7

6. Lee W, Bindman J, Ford T, Glozier N, Moran P, Stewart R, Hotopf M (2007) Bias in psychiatric case-control studies: literature survey. Br J Psychiatry 190:204-209

7. Rimvall MK, Elberling H, Rask CU, Helenius D, Skovgaard AM, Jeppesen P (2014) Predicting ADHD in school age when using the Strengths and Difficulties Questionnaire in preschool age: a longitudinal general population study, CCC2000. Eur Child Adolesc Psychiatry 23(11). doi:10.1007/s00787-014-0546-7

8. Roessner V (2014) Research in child and adolescent psychiatry: a multi-disciplinary, many-faceted endeavor. Eur Child Adolesc Psychiatry 23:1-2

9. Sackett DL, Rosenberg WM, Gray JA, Haynes RB, Richardson WS (1996) Evidence based medicine: what it is and what it isn't. BMJ 312:71-72

10. Serafini G, Pompili M, Borgwardt S, Houenou J, Geoffroy PA, Jardri R, Girardi P, Amore M (2014) Brain changes in early-onset bipolar and unipolar depressive disorders: a systematic review in children and adolescents. Eur Child Adolesc Psychiatry 23(11). doi:10.1007/s00787-014-0614-z

11. Silva D, Colvin L, Hagemann E, Stanley F, Bower C (2014) Children diagnosed with attention deficit disorder and their hospitalisations: population data linkage study. Eur Child Adolesc Psychiatry 23(11). doi:10.1007/s00787-014-0545-8

12. van den Hoofdakker BJ, Hoekstra PJ, van der Veen-Mulders L, Sytema S, Emmelkamp PMG, Minderaa RB, Nauta MH (2014) Paternal influences on treatment outcome of behavioral parent training in children with attention-deficit/hyperactivity disorder. Eur Child Adolesc Psychiatry 23(11). doi:10.1007/s00787-0140557-4

13. Vineis P, Kriebel D (2006) Causal models in epidemiology: past inheritance and genetic future. Environ Health 5:21 